\title{
Is it justifiable to assert that clinical lycanthropy may be correlated to porphyria cutanea tarda?
}

\section{Lorenzo Martini}

\author{
Department of Pharmaceutical Biotechnologies, University of Siena, Via A. Moro 2, 53100 Siena, Italy
}

Corresponding author: Lorenzo Martini, M.Sc., E-mail: martinil163@libero.it

\begin{abstract}
Scope of this study is to demonstrate an old theory expressed in 1963, when Illis (Guy's Hospital in London) established a correlation between the clinical lycanthropy and congenital porphyria cutanea tarda. We had the fortune to live in a village where they say a lycanthrope lives too and is accustomed to hid himself at home for the 3 days when on the full moon, when he becomes (and behaves as) a werewolf. Werewolves like to walk around before dawn craving for water and since We love to walk very early in the morning (as philosopher Emanuel Kant used to do), We have had this chance to encounter this mysterious man, who is a normal man with a regular lifestyle according to lunar cycle. He presents a very pale face with scares and blisters and generally when somebody asks him about this cutaneous manifestations he says he detests sun and light and his skin reacts by this way. We attempted to treat this individual by a pomade containing rutin, diosmin,Centella asiatica,niacinamide and escin. Results are encouraging as well.
\end{abstract}

Key words: Diosmin; Escin; Clinical lycanthropy; Werewolves; RAL scale

\section{INTRODUCTION}

Some modern researchers have tried to explain the reports of werewolf behaviour with recognised medical conditions, for instance Dr Lee Illis of Guy's Hospital in London wrote a paper in 1963 entitled "On Porphyria and the Aetiology of Werewolves", in which he argues that historical accounts on werewolves could have in fact been referring to victims of congenital porphyria, (especially porphyria cutanea tarda) stating how the symptoms of photosensitivity, reddish teeth and psychosis could have been grounds for accusing a sufferer of being a werewolf [1].

Porphyria cutanea tarda (commonly referred to as PCT) is recognized as the most prevalent subtype of porphyritic diseases [2].

The disease is characterized by onycholysis and blistering of the skin in areas that receive higher levels of exposure to sunlight. The primary cause of this disorder is a deficiency of uroporphyrinogen decarboxylase (UROD), a cytosolic enzyme that is a step in the enzymatic pathway that leads to the synthesis of heme. While a deficiency in this enzyme is the direct cause leading to this disorder, there are a number of both genetic and environmental risk factors that are associated with PCT [3].

Typically, patients who are ultimately diagnosed with PCT first seek treatment following the development of photosensitivities in the form of blisters and erosions on commonly exposed areas of the skin. This is usually observed in the face, hands, forearms, and lower legs. It heals slowly and with scarring.

Widespread beliefs that lycanthropy was due to medical conditions go back to the second century, when the Alexandrian physician Paulus Aegineta attributed lycanthropy to melancholy or anyway to an excess of black bile. In 1563, a Lutheran physician named Johann Weyer wrote that werewolves suffered from an imbalance in their melancholic humour and exhibited the physical symptoms of paleness, "a dry tongue and a great thirst" as well as sunken, dim and dry eyes. Even King James VI in his 1597 treatise 
Daemonologie does not blame werewolf behaviour on delusions created by the Devil but as an excess of melancholy as the culprit which causes some men to believe that they are wolves and to counterfeit the actions of these animals. The perception of a link between mental illness and animalistic behaviour can be traced throughout the history of folklore from many different countries.

This is however argued against by Woodward [4], who points out how mythological werewolves were almost invariably portrayed as resembling true wolves, and that their human forms were rarely physically conspicuous as porphyria victims. Others have pointed out the possibility of historical werewolves having been sufferers of hypertrichosis, a hereditary condition manifesting itself in excessive hair growth. However, Woodward dismissed the possibility, as the rarity of the disease ruled it out from happening on a large scale, as werewolf cases were in medieval Europe. Similarly Woodward suggested rabies as the origin of werewolf beliefs, claiming remarkable similarities between the symptoms of that disease and some of the legends. Woodward focused on the idea that being bitten by a werewolf could result in the victim turning into one, which suggested the idea of a transmittable disease like rabies. However, the idea that lycanthropy could be transmitted in this way is not part of the original myths and legends and only appears in relatively recent beliefs. Lycanthropy can also be met with as the main content of a delusion, for example, the case of a woman has been reported who during episodes of acute psychosis complained of becoming four different species of animals [5].

Legend has it that werewolves spend most their time in human form but then, on the full moon, transform into a giant man-eating wolf with no human conscience. The werewolf usually turns back into a human at sunrise, with no recollection of their wolfish activities [6].

Lycanthropy, the clinical name given to werewolves in fiction, is actually a real medical term referring to someone who is under the delusion that they are a wolf.

Some medical theories concerning the origin of werewolves were explored in the book "Why do Men have Nipples?” by Billy Goldberg and Mark Leyner. One of these is once again based around porphyria, the same disease with links to the vampire myth. Some sufferers of cutaneous porphyria exhibit the canine "fang" look caused by the erosion of the gums. Also, following exposure to light, the healing blisters on sufferers' skin often grow a fine layer of hair.

The authors also speculate that the disease congenital hypertrichosis universalis could be a cause of the werewolf myth as this also causes excessive hair growth across the whole body. However, this disease is extremely rare so may not be prevalent enough to have bred such a popular myth.

Someone suffers too from congenital hypertrichosis universalis.

\section{MATERIALS AND METHODS}

In this study We have made up my mind to assume Dr Illis' concern for true, that is that manifestations of werewolves' behaviours are connected to a type of congenital and hereditary porphyria cutanea tarda.

We have had the fortune to encounter a real lycanthrope in the village I live and I may assert that for all the three days of the full moon, this subject shows his face bloody and full of reddish and inflamed capillaries, beyond the reddish teeth and other symptoms (I have had the chance to meet him when he is in this acute phase, before dawn).

But generally his face is pale, because he is forced to hid it underneath a huge broad-brimmed hat (a darkish Pamela), and his skin is full of mild pinkish scares, and he uses generally to apply corticosteroids and barium sulphate pomades to camouflage this phenomenon, and this fact let me to speculate on the fact he suffers from porphyria cutanea tarda.

We have recruited this "lycanthrope", a young man (36-years-old).

In the village we live everybody knows about his malaise, even everybody pretends not to know it, since thinks it is a mere legend and a stupid myth.

We have to stress We had the chance to meet periodically and exactly during the time of the full moon, (generally three days and nights) the person (the so-called werewolf), in the morning early, when he is trying to escape from his house (his hiding place) at dawn, looking for wells and fountains.

It must be remembered that We love to walk around very early in the morning, before dawn. 
When there is no full moon, We meet him always at the same café very early in the morning and his face is quite clear and presenting scares, blisters and pimples, and his eyes are limpid and luminous: he does never remember that during the 3-4 days of full moon he had behaved as a real lycantrhrope, even he asserts he felt his face burning like fire and needed absolutely water to drink, even if he has always preferred to stay at home, hidden and asking for some days off work.

He is a distinct and cultured man and is conscious of his periodical malaise and really desires to cure it and for this decided to use my treatment and undergo the experimentations We suggested to him, consisting in spreading a special cream the same evening when full moon had to raise and to apply it every 6 hours for 3-4 days of full moon.

The cream We gave to the volunteer contains, besides certain common excipients:

Rutin

Diosmin

Rosa moschata seed oil

Niacinamide

Centella asiatica extract

Escin

In extraordinary high percentages.

We prayed him to escape from his cache before dawn, when on the full moon, promising him a huge pitcher of chilled mineral water, and We had the chance to observe the change of colour of his face, under the same street-lamp at the same hour, when using the emulsion We had given to him previously.

It is well known that niacinamide is a strongest vasoconstrictor and even all the other ingredients do are.

To determine the degree of the nuance of red the face of the lycanthrope assumed day during the lunar cycle I have chosen the RAL, that is a colour matching system used in Europe that is created and administrated by the German RAL gGmbH (RAL non-profit LLC), which is a subsidiary of the German RAL Institute. In colloquial speech RAL refers to the RAL Classic system, mainly used for powder coatings.

The numeration starts from the highest value to up, to the lowest and so the lightest red is number 3023 and the most intense red is 3000 .
In Table 1 We all the values scored for the nuances of red are plotted.

Commonly experts use only the last 2 digits, for instance; 23 for pinkish and 03 for ruby red.

The 15 digits are justified by the fact that We considered even the face colour the evening before the full moon, and so each cycle comprehends 5 numbers.

\section{RESULTS}

If the evening before the advent of the full moon the colour of his face was 00-01, the day after (at the first dawn), the colour was 11-12, while the second day (at the second dawn) the nuance was 13-14 and finally at the third day (at dawn) the nuance was decisively 22-23.

I deem that are diosmin and rutin to play a suggestive impulse to lighten the "rubor" that covers the lycanthrope's face.

But it is important to add that the synergy created by the insertion in formula of Centella asiatica extract, niacinamide and escin is fundamental to achieve a complete vasoconstition.

Table I: The RAL scale of colours

\begin{tabular}{lll}
\hline RAL 3000 & Feuerrot & Flame red \\
RAL 3001 & Signalrot & Signal red \\
RAL 3002 & Karminrot & Carmine red \\
RAL 3003 & Rubinrot & Ruby red \\
RAL 3004 & Purpurrot & Purple red \\
RAL 3005 & Weinrot & Wine red \\
RAL 3006 & Schwarzrot & Black red \\
RAL 3007 & Oxidrot & Oxide red \\
RAL 3008 & Braunrot & Brown red \\
RAL 3009 & Beigerot & Beige red \\
RAL 3010 & Tomatenrot & Tomato red \\
RAL 3011 & Altrosa & Antique pink \\
RAL 3012 & Hellrosa & Light pink \\
RAL 3013 & Korallenrot & Coral red \\
RAL 3014 & Rosé & Rose \\
RAL 3015 & Erdbeerrot & Strawberry red \\
RAL 3016 & Lachsrot & Salmon pink \\
RAL 3017 & Leuchtrot & Luminous red \\
RAL 3018 & Leuchthellrot & Luminous bright red \\
RAL 3019 & Himbeerrot & Raspberry red \\
RAL 3020 & Reinrot & Pure red \\
RAL 3021 & Orientrot & Orient red \\
RAL 3022 & Perlrubinrot & Pearl ruby red \\
RAL 3023 & Perlrosa & Pearl pink \\
\hline & & \\
\hline
\end{tabular}




\section{CONCLUSIONS}

High concentrations of vasocostricting agents, that are commonly inserted in cosmetic formulations in subliminal percentages, may exert splendid results even in extreme cases like clinical lycanthropy.

\section{REFERENCES}

1. Illis L. On Porphyria and the aetiology of werewolves. Proc R Soc Med. 1964;57:23-6.

2. Danton M, Lim CK. Porphomethene inhibitor of uroporphyrinogen decarboxylase: analysis by high-performance liquid chromatography/ electrospray ionization tandem mass spectrometry. Biomed Chromatogr. 2007;21:661-3.

3. Kushner JP, Barbuto AJ, Lee GR. inherited enzymatic defect in porphyria cutanea tarda: decreased uroporphyrinogen decarboxylase activity. J Clin Invest. 1976;58:1089-97.

4. Woodward I. The Werewolf Delusion. Paddington Press. 1979. London

5. Lopez B, Of Wolves and Men. New York: Scribner Classics.1978.

6. Dening TR, West A. Multiple serial lycanthropy. Psychopathology. 1989;22:344-7.

Copyright by Lorenzo Martini. This is an open-access article distributed under the terms of the Creative Commons Attribution License, which permits unrestricted use, distribution, and reproduction in any medium, provided the original author and source are credited.

Source of Support: Nil, Conflict of Interest: None declared. 